\section{Undergraduate STEM Majors on and off the Pre-Med/Health Track: A STEM Identity Perspective}

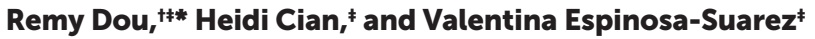 \\ 'Department of Teaching and Learning and ISTEM Transformation Institute, Florida International \\ University, Miami, FL 33155
}

\begin{abstract}
Despite the wealth of research exploring science, technology, engineering, and mathematics (STEM) identity and career goals in both formal and informal settings, existing literature does not consider STEM identity for undergraduate students pursuing health and medical careers through STEM pathways. We address this gap by examining the STEM identity of undergraduate STEM majors on pre-med/health tracks as it compares with that of other STEM majors, thus focusing on a population that is chronically understudied in STEM education research. We surveyed 440 undergraduate STEM students enrolled in entry-level STEM courses to assess their STEM identities and three identity precursors: interest, performance-competence, and recognition. Through regression analyses accounting for gender, major, and perceived home support around STEM, we found that pre-med/ health students were more likely to have higher STEM identity and recognition scores than their peers; we did not detect a significant difference for performance-competence or interest in STEM. Although there is little tracking of pre-med/health students' ultimate career attainment, the implications of our findings support a potential for sustaining pre-med/ health students while simultaneously creating pathways to other STEM pursuits for the nearly $60 \%$ of those who do not enter medical school by offering participation in experiences that affirm their STEM identities.
\end{abstract}

\section{INTRODUCTION}

Recent trends in STEM ${ }^{1}$ education research signal an increase in the use of identity frameworks to explore undergraduate student outcomes. Identity frameworks have been applied to research on undergraduate student learning (e.g., Mraz-Craig et al., 2018; Seyranian et al., 2018; Robinson et al., 2019), STEM career choice (e.g., Hernandez et al., 2017; Stets et al., 2017; Estrada et al., 2018), and persistence to STEM degree completion (e.g., Estrada et al., 2016; Taheri et al., 2018; Robinson et al., 2019). For example, the work of Dou et al. (2019) highlights a strong association between undergraduate students' STEM identities (i.e., the degree to which they see themselves as a "STEM person") and their intentions to continue pursuing STEM careers. Similar to Dou and colleagues' work, much undergraduate STEM identity research has focused on populations of students pursuing STEM degrees (e.g., Nadelson et al., 2017; Morton and Parsons, 2018; Rodriguez et al., 2019), but the phenomenon of STEM identity within a population defined by medical and health career pursuits has not been well explored (Larson et al., 2012). Given the different perspectives around STEM and STEM education, understanding what counts as "STEM" and who count as "STEM people" in relation to those pursuing health or medical careers has far-reaching implications relevant to the undergraduate student experience, including access to career

"Here we use the term "STEM" as a catchall term referring to a broad spectrum of subfields related to science, technology, engineering, and mathematics, including health and medicine.
Erika Offerdahl, Monitoring Editor

Submitted Dec 9, 2020; Revised Feb 9, 2021; Accepted Mar 3, 2021

CBE Life Sci Educ June 1, 2021 20:ar24

DOI:10.1187/cbe.20-12-0281

*Address correspondence to: Remy Dou (redou@fiu.edu).

(c) 2021 R. Dou et al. CBE-Life Sciences

Education ๑ 2021 The American Society for Cell Biology. This article is distributed by The American Society for Cell Biology under license from the author(s). It is available to the public under an Attribution-Noncommercial-Share Alike 3.0 Unported Creative Commons License (http://creativecommons.org/licenses/ by-nc-sa/3.0).

"ASCB®" and "The American Society for Cell Biology $® "$ are registered trademarks of The American Society for Cell Biology. 
funding support (e.g., scholarships, grants, fellowships) and research opportunities (e.g., employment in STEM labs funded by STEM agencies), as well as implications relevant to education researchers who work with STEM students.

Understanding the identity perspectives of STEM majors on a pre-med/health ${ }^{2}$ track is of particular importance due to 1) the relative few who actually go to medical school, which implies that many do not enter their intended careers; 2) the general omission of the population from conversations about supporting STEM education and retention; and 3) stereotypes of the profile of pre-med/health students-each of which we discuss in more detail later. Given the many career-related phenomena associated with identity, developing this understanding of the STEM identity of pre-med/health students is important both for supporting their success using identity-based interventions and addressing issues of persistence and retention in STEM fields in general (National Research Council [NRC], 2012; National Science Board, 2020).

Here, we present a quantitative comparative study that explores the relationship between undergraduate students' $(N=440)$ interest in STEM fields, their sense that their teachers recognize them as STEM people, their confidence to succeed on STEM-related exams, and their overall self-perceptions as STEM people. Specifically, we explore differences between STEM majors on a pre-med/health track and STEM majors not pursuing medical careers. Although "pre-med" and "pre-health" are unique categorizations-with "pre-med" referring to students who intend to enroll in medical school and "pre-health" to students who aspire to related careers in health fields (e.g., physician assistant, nurse)-these students share identity-related experiences in their aim to acquire specialized, postbaccalaureate training. This sets them apart from their peers majoring in STEM who aspire to join nonmedical professions. In addition, we account for relevant factors, including 1) participants' self-reported gender, which consistently demonstrates a contribution to self-perception in STEM (e.g., Archer et al., 2013; Kim et al., 2018; Seyranian et al., 2018; Starr, 2018; Witherspoon et al., 2019); 2) home support, drawing from literature noting the influence of parental activity on STEM identity construction (e.g., Gokpinar and Reiss, 2016; Dou et al., 2019; Pattison and Dierking, 2019); and 3) whether or not a student is a biology major, acknowledging the substantial representativeness of this major within groups of students on a pre-med/health track (Cotner et al., 2017). In the following sections, we summarize and synthesize relevant research exploring the undergraduate pre-med/health experience, provide a brief overview of our identity framework, situate the purpose of our study in light of existing literature, describe our methods and results, and discuss the implications of our findings.

\section{LITERATURE REVIEW}

\section{Pre-Med/Health Students and STEM Majors}

In 2015, the great majority of physicians surveyed by the U.S. Bureau of Labor Statistics reported having started off their

${ }^{2}$ Here and throughout the rest of this article, we use the term "pre-med/health" to refer broadly to students who aspire to careers in health-related fields, including those intending to become physicians, nurses, pharmacists, and/or physical therapists, all of which require additional academic preparation beyond an undergraduate degree. When referencing particular studies, we adopt their terminology. careers as STEM majors at undergraduate institutions with nearly half enrolled as biological sciences majors and approximately $15 \%$ as physical sciences majors (e.g., chemistry, physics; Chen, 2017). Other STEM-related majors included engineering, mathematics, and social sciences. However, national reports and research studies that address the success of STEM majors often fail to include or address pre-med/health students specifically, either by intentionally excluding them or neglecting to account for them as a distinct demographic population. The National Science Board, for example, whose primary role is to "serve as an independent body of advisors to both the President and the Congress on policy matters related to science and engineering and education in science and engineering" (National Science Board, 2020, p. 1), does not count healthcare professionals as part of the science and engineering workforce (National Science Foundation [NSF], 2020). More surprising might be the National Research Council's publication on discipline-based education research (NRC, 2012), which, despite its focus on research in undergraduate science and engineering, does not address or allude to any studies that focus on pre-med/ health students or their classroom experiences. Even the iconic NRC report, BIO2010: Transforming Undergraduate Education for Future Research Biologists (2003), explicitly describes its exclusion of this population of students while highlighting the tremendous pressure that medical school requirements place on the course offerings and curricula of biology and other STEM departments, all in the same paragraph. Similarly, while some attention is given to biomedical research in the White House's strategic plan for STEM education, no attention is given to the healthcare enterprise as a whole, despite the participation of 15 federal agencies, including the NSF, the National Aeronautics and Space Administration, and the Department of Energy (Committee on STEM Education, 2018). Absent from this report were representatives from the National Institutes of Health, which focuses on health-related research and fields. The level of attention given by federal agencies to programs that support STEM majors, particularly those who intend to pursue health and medical careers, matters, given its effect on funding, directions taken up by the STEM education research community, and programmatic development.

Understanding the experiences of pre-med/health majors and their identification with STEM is critical in supporting their success and addressing needs of health fields broadly, including issues of underrepresentation (e.g., National Academies of Sciences, Engineering, and Medicine [NASEM], 2020). For instance, Emery et al. (2018) propose interventions in STEM identity could increase participation of underrepresented minorities in health professions. Understanding the extent to which pre-med/health students identify with STEM broadly is important, given that most physicians begin undergraduate education as STEM majors but fewer than half of medical school applicants (e.g., 41\% in 2019; Association of American Medical Colleges, 2020) are accepted and enrolled in a U.S.based medical school each year. The obvious implication is that more than half of the students who intend to enter medical school in the United States do not, and therefore they must make new educational and career plans late in their undergraduate careers, or, for the many who defer applying until after graduation, once they no longer have access to university career support resources. Despite the large number of students who 
experience this imperative to rethink their medical career aspirations, what happens to those applicants, and perhaps more importantly, whether or not they can be retained in STEM fields, is not well understood.

Villarejo et al. (2008) offers one of the few studies that obliquely considers where some of these premed STEM majors who do not become physicians or other healthcare professionals end up. They surveyed 322 alumni of an undergraduate intervention program for underrepresented minorities majoring in biology about their subsequent careers and the elements of their experience that contributed to their career choices. Of those who at the time of the survey were pursuing $\mathrm{PhD}$ degrees in biomedicine $(n=24)$, "nearly half" $(n=11)$ had originally intended to become doctors, and some of those attributed this career change to undergraduate research experiences that "revealed career options they had not previously considered" (p. 403). Though the authors acknowledged that other studies suggest that research experiences solidify career intentions but do not change them, they point to weaknesses in these studies regarding their lack of accounting for the relative privilege of their participants (e.g., they may be more aware of careers in research) and assessments of the research experiences late in the students' college careers (e.g., the summer before senior year). In this way, they suggest that these experiences may be particularly valuable for revealing career opportunities for underrepresented minority students early in their college careers. Still, even though this work provides a glimmer of insight on the phenomenon of attrition in the medical career pathway, the small sample and bounded context of the study is difficult to interpret more broadly.

Despite calls to address the pre-med/health experience, little research exists in this area, with much of what is available published before 1990 (Lin et al., 2013), and even fewer studies have explored how STEM majors on a pre-med/health track differ from those not seeking health-related careers (Larson et al., 2012). In some cases, it is simply assumed that these students differ from other STEM students in terms of STEM identity, which has implications for how findings from these studies can be interpreted and applied. For instance, McDonald et al. (2019) surveyed college and university students across the state of Alabama and divided the students into comparison groups of "Non-STEM," "Soft-STEM," "Hard-STEM," and "Health" categories as part of their construct validity analysis of a proposed STEM identity measure (drawing from definitions of "hard" and "soft" STEM by Biglan, 1973). This was done to determine whether their instrument "would detect differences in identification with STEM between students majoring in a STEM field vs. those in non-STEM fields" (McDonald et al., 2019 , p. 6), though it is not clear whether they considered the "Health" students as STEM or non-STEM. In any case, this decision to differentiate "Health" students from other STEM students in their grouping implies some expectation of differences between the groups on their STEM identity construct, yet they did not address from where this expectation arose. Understanding the extent to which pre-med/health students can, in fact, be expected to differ from other STEM students has implications for how STEM identity researchers should construct their study populations (i.e., whether pre-med/health students should or should not be included) and the types of recommendations and generalizations they may be able to make from their work (e.g., whether findings may be expected to apply to pre-med/ health populations).

\section{Perceptions of Pre-Med/Health Students}

Undergraduate faculty's perceptions of students pursuing medical or health-related careers have also been shown to have far-reaching implications for students' undergraduate experiences (Sade et al., 1984). Often these students are "perceived differently from Non-Pre-Medical students in being excessively competitive, academically overspecialized, overachieving, more highly motivated, more highly self-disciplined, goal-oriented, and proud of their career choice" (Sade et al., 1984, p. 1). However, a synthesis of available literature published from the mid1980s to 2010 on the pre-medical student experience in the United States revealed that the "Pre-Medical stereotype was more perception than an observed reality" (Lin et al., 2013, p. 34). Throughout the literature reviewed by Lin et al. (2013), Pre-Medical students were observed to be similar to their nonPre-Medical peers in terms of concern about grades and competitiveness, despite stereotypes suggesting the contrary. The reviewed research also suggested that Pre-Medical students were more interested in taking a variety of courses-both STEM and non-STEM-even if those courses were perceived to be challenging (i.e., not just a grade point average boost).

Also exploring the attitudinal similarities and differences between STEM majors pursuing or not pursuing medical or health occupations, Larson et al. (2012) compared undergraduate students ( $N=165$, all but four in science majors) based on their educational and postgraduate intentions: careers in medicine (i.e., identified as "Pre-Med" and defined to include a broad group of health-related careers), a graduate degree, or a bachelor's degree. The authors found that the undergraduate Pre-Med group had higher science and math self-efficacy, interest, and goals (e.g., intention to enter a science career, willingness to take more than the required science courses) than those in the bachelor's degree group and significantly higher goals than the students who intended to pursue graduate degrees. Horowitz's (2009) work on motivations of male pre-med students aligns well with these findings. Her qualitative work found that very few students (four out of 31) were primarily motivated by external rewards such as grades; in contrast, a third of the students stated that their main purpose in college was learning and "that they typically sought courses across all subject areas that would challenge them intellectually" (p. 225), with one student commenting, "[I] wouldn't think twice" (p. 226) about taking an interesting course even if a good grade was not guaranteed.

These findings stand in contrast to widely recognized (though anecdotal) perceptions of pre-med/health students held by STEM faculty, such as that they are only interested in getting good grades (e.g., Conrad, 1986; Liang, 2012; Moss, 2018). Particularly, the finding that compares science and math goals suggests that pre-med/health students see value in learning more science and math than may be required of them. Though this finding could be explained as a willingness to have more experiences so that they are better prepared to succeed on the Medical College Admission Test (MCAT) or in their medical school studies, it is still suggestive of a willingness to get more out of their undergraduate experience than good grades. Still, these stereotypes continue to persist, and their persistence has potentially 
far-reaching consequences. For example, given that faculty exercise discretion in selecting undergraduate research assistants, stereotypes about pre-med/health students could remove them from consideration for these types of opportunities.

Revisiting the myths surrounding pre-med/health majors from the perspective of STEM identity could also provide new avenues for addressing deficits in the nonmedical STEM workforce (e.g., National Science Board, 2015; Xue and Larson, 2015; NASEM, 2016; Dou et al., 2019) and persistent challenges to retain minorities in nonmedical STEM fields (e.g., Chang et al., 2014; Wong, 2015; Estrada et al., 2016). This would apply to issues of underrepresentation in disciplinary areas like physics (Lock and Hazari, 2016) and chemistry (Fink et al., 2020), while simultaneously addressing similar issues in medical fields (Emery et al., 2018; Lett et al., 2018; NASEM, 2020). For example, undergraduate research experiences in basic science that explicitly invite the participation of pre-med/health students could serve to align students "with a research scientist identity by pursuing work in a research laboratory early on in [their] undergraduate career[s]" (Carlone and Johnson, 2007). In seeing themselves and feeling recognized as valuable participants in the STEM enterprise, these students are more likely to achieve their STEM-related career goals, be they in medical or nonmedical careers (Estrada et al., 2018; Dou et al., 2019).

\section{THEORETICAL FRAMEWORK}

The construct of identity, or how individuals perceive themselves and engage others as a particular "kind of person" (Gee, 2000 , p. 99), has been implicated in research of academic performance, engagement, career choice, and persistence in STEM-related contexts in both formal and informal learning settings (e.g., Carlone and Johnson, 2007; Hazari et al., 2010; Dou et al., 2019; Morris et al., 2019; Avraamidou, 2020; Goff et al.; 2020). Identity researchers focusing on undergraduate STEM career choice and persistence have generally explored these factors without accounting for students' post-bachelor degree intentions, instead tending to study students enrolled in particular majors, such as physics (Hazari et al., 2010; Seyranian et al., 2018) or engineering (Godwin et al., 2016), or those pursuing STEM majors in general (Dou and Cian, 2020; Goff et al., 2020). Though this type of research is valuable in understanding students' self-perception within STEM broadly or within specific STEM disciplines, tendencies to define STEM populations by college major restrict the implications and utility of research beyond the major-specific context. Students who intend postgraduate education may enter their professional careers from a variety of majors; for instance, those who ultimately go to medical school may major in STEM or even nonSTEM subjects, just as those who decide to enroll in law school may major in any number of fields. Given the implications of identity on factors of interest to educators and education researchers, as noted earlier, extending STEM identity research to a population as defined by career intentions is a necessary pursuit, particularly regarding efforts to address needs of the STEM workforce and especially with a population such as premed/health students in which so many do not end up in their choice of profession. Our research focuses on this gap in the literature and is guided by a general desire to better understand the motivators and support structures of undergraduate STEM majors pursuing pre-med/health careers.
In general, STEM identity researchers posit that individuals engage in activities and with communities in ways that both construct and reflect the various facets of their being (Gee, 2000; Urrieta, 2007; Avraamidou, 2020). Given this link between how individuals identify and the activities they engage in, research on identity is particularly valuable in contexts related to career choice and career persistence. Nevertheless, the way individuals identify is neither static nor singular, but rather an overlapping product of both performative and cognitive processes that are shaped by historical, political, social, and contextual variables (Avraamidou, 2020). In other words, the specific contexts individuals find themselves in and their experiences in those contexts create a "push-and-pull" effect on their identity development over time as they negotiate the extent to which they participate along with their perception of how others react to their participation (Calabrese Barton et al., 2013). Research in STEM identity consistently documents this effect on girls, for example, highlighting the effects of masculine stereotypes of STEM engagement as an impediment to their capacity to see themselves in STEM (e.g., Archer et al., 2013; Heybach and Pickup, 2017; Ong, 2005). For instance, Archer et al. (2013) studied the perceptions of 10- to 11-year-old girls and their parents, noting a clear divergence in their perceptions of femininity and stereotypes of scientists as "brainy" or "geeky" (p. 188), which contributed to impediments in their self-perceptions as actors within the scientific enterprise. Our exploration of STEM identity builds specifically off the work of Carlone and Johnson (2007) and Hazari et al. (2010). Both of these research teams employ a personal identity framework that focuses on measuring the extent to which a person identifies with and has affinity toward a general (or particular) field of study (e.g., Luhtanen and Crocker, 1992). While personal identity frameworks focus on the perceptions of the individual, they also account for social and contextual factors that contribute to how individuals see themselves. Both Carlone and Johnson (2007), who address conceptions of science identity in general (e.g., "I see myself as a science person"), and Hazari et al. (2010), who address conceptions of discipline-based identity (e.g., "I see myself as a physics person"), posit three primary factors as contributing to the development of one's STEM identity: recognition, interest, and performance-competence (see Figure 1).

\section{Recognition, Interest, and Performance-Competence in STEM}

Of the three primary STEM identity precursors, "recognition" stands out as the most critical both conceptually and in terms of effect size. Gee (2000) puts it this way: "at root, human beings must see each other in certain ways and not others if there are to be identities of any sort" (p. 109). Recognition in STEM contexts is particularly salient in light of racial, ethnic, and gender-based biases that favor the dominant archetype of the scientist as white and male (e.g., Carlone and Johnson, 2007; Diekman et al., 2011; Hazari and Cass, 2018; Avraamidou, 2020). Following Carlone and Johnson's (2007) identity framework, we specifically define STEM "recognition" as an individual's belief or perception that significant others consider them to be a STEM person. In our work we focus exclusively on the role of teachers, given the academic setting our participants find themselves in and the career-focused context of our work. 


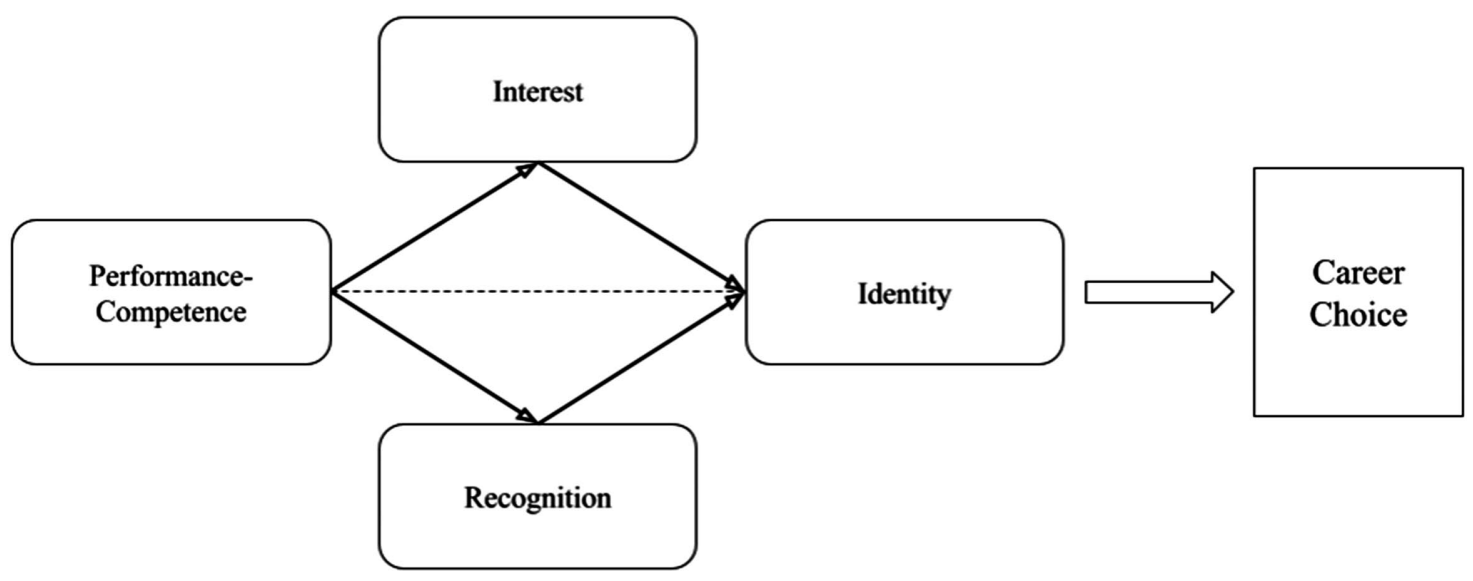

FIGURE 1. Conceptual framework for understanding the relationships between STEM identity, interest, recognition, performance-competence, and career choice. Although performance-competence is not usually directly predictive of STEM identity, its indirect effects are typically larger than the direct effects of STEM interest, while STEM interest and recognition are often significantly correlated with one another. Adapted from Godwin et al., 2016.

However, we do acknowledge the powerful role that alternative significant others may exert on STEM identity, particularly parents. For instance, much research supports the suggestion that home support factors influence individuals' STEM dispositions, sense of recognition in STEM, and STEM identity (Archer et al., 2015; Dou and Cian, 2020; Gokpinar and Reiss, 2016; Pattison and Dierking, 2019). Gokpinar and Reiss (2016) position this support, for instance, in the form of visiting science centers or providing science toys or reading materials as conversion factors existing at the intersection of social and cultural factors and identity-related outcomes, such as aspiration to science careers.

Historically, interest in STEM topics and concepts has been seen as a primary motivator of young people's STEM-related career choices, as well as their identity development (e.g., Archer et al., 2010; Taskinen et al., 2013; Wong, 2015). Lent et al.'s (1994) social cognitive career theory, which builds off Bandura's social cognitive theory $(1989,2001)$, posits "interest" development as an essential precursor to career-related goal setting and behavior. Grounded in this work, we define interest as a desire to learn more about STEM. While identity frameworks used in STEM contexts recognize an association between sense of recognition and interest in STEM, these are generally operationalized as unique contributors.

On the other hand, quantitative models in various STEM contexts have found that performance-competence, that is, individuals' sense of both their ability to perform STEM tasks, as well as understand STEM concepts (Carlone and Johnson, 2007; Hazari et al., 2010), does not act directly on individuals' STEM identities but rather as mediated through their interest and recognition in STEM (Cass et al., 2011; Cribbs et al., 2015, 2016; Godwin et al., 2016). In some cases, studies have shown that the indirect effect of college students' performance-competence in STEM on their STEM identities is greater than the direct effect of their interest in STEM (Godwin et al., 2016), underscoring the significance of this variable in light of the attention given to STEM interest. While individuals may participate in STEM in many contexts and thus have varying degrees of confidence in their performance across these contexts, in this research, we measure performance in a particular context familiar to our college student population, that is, performance on tests or exams in STEM subjects.

\section{PURPOSE AND RESEARCH QUESTIONS}

The purpose of this study is to understand the extent to which STEM majors on a pre-med/health track identify as STEM people relative to STEM majors not on a pre-med/health track, as well as how they might differ across identity-related factors, while accounting for student gender, home science support (operationalized as engaging in out-of-school science activities with their families), and their pursuit of a biological sciences major. Specifically, we aim to address the following research questions:

1. To what extent does the STEM identity of STEM majors on a pre-med/health track differ from that of STEM majors not on a pre-med/health track?

2. How do factors contributing to STEM identity (i.e., interest, performance-competence, recognition) differ for STEM majors on a pre-med/health track from those of STEM majors not on a pre-med/health track?

3. How do gender, home science support, and biological sciences major contribute to variances across identity related variables?

\section{METHODS AND METHODOLOGY Population}

This research is part of a broader study exploring young people's STEM identity development across formal and informal learning environments. Data collection took place at a large, Research I, Hispanic-serving institution located in the southeastern region of the United States. We sampled undergraduate students by securing email addresses from all those enrolled in entry-level STEM courses at the time of data collection (i.e., Fall semester of 2019). To generate this sample, we accessed course enrollments for the following lower-division courses present in the programs of studies for STEM majors at the institution: 
Calculus I, Chemistry \& Society, General Chemistry I, General Chemistry II, General Biology I, General Biology II, Introductory Physics I and II (both with and without calculus), and Statistics I. We removed duplicates (e.g., students enrolled in both General Chemistry and Calculus I) and emailed students a link to a digital survey. The survey went out to 5678 students of whom 522 responded-a response rate of roughly $9.2 \%$. Because our research purpose is to compare the STEM identity of STEM majors in pre-med/health tracks with those not in premed/health tracks, we removed respondents who did not indicate pursuit of a STEM major $(n=26)$ and those who did not provide their majors $(n=56)$. The remaining 440 students indicated that they were enrolled in STEM majors by selecting one of the following options: physics, biological sciences, chemistry, engineering, mathematics, earth science/geoscience, computer science, and "other STEM major." We included this last category to capture respondents who did not affiliate with the above but still considered their majors to be "STEM." Among the respondents, 53\% were biology majors. We also asked participants to self-identify as being a "pre-med" or "pre-health" student (single item; binary response). Although the institution where this work took place offered an official "health sciences" track, at the time of the study, this track only existed for a few years and it was offered as an exploratory major to students unsure of their undergraduate career goals. The institution did not offer a specific major for students pursuing postgraduate medical or health-related studies, despite our use of the phrase "pre-med/ health track." Respondents who identified as pre-med/health students composed $61 \%$ of our respondent sample.

\section{Identity-Related Items}

Identity-related items were drawn and modified from Hazari et al.'s (2010) discipline-based identity framework to measure STEM identity broadly, as well as the identity precursors. Students were presented with statements relevant to these four variables and asked to rate their level of agreement using a fivepoint Likert scale anchored only at the poles: "strongly disagree" to "strongly agree." We measured STEM identity as the dependent variable using the statement "I see myself as a STEM person." This approach follows Shanahan's (2008) operationalization of identity in survey instruments as the degree to which individuals perceive themselves as a "type of person." Our other three variables of interest were also measured using single items and included STEM interest ("I am interested in learning more about STEM"), recognition ("My teachers see me as a STEM person"), and performance-competence ("I can do well on tests and exams in STEM"). We achieved a Cronbach's alpha measure of reliability for our four identity-related items of 0.81 (95\% confidence interval: 0.78-0.83). For correlations across these four items, please see Supplemental Table 1.

In selecting the item statements listed, we sought to account for the fact that they represent complex constructs and can therefore be difficult to measure with sufficient validity using single items (although constructs as complex as self-efficacy have been measured adequately using single items; e.g., Hoeppner et al., 2011). Our choice to use single-item measures is predicated on our intention to highlight specific attributes of the constructs and their relation to identity and pre-med/health status rather than the constructs broadly, while also relying on measures that will be applicable to all students in our popula- tion. For instance, not all students, particularly those enrolled in introductory STEM courses early in their undergraduate careers, have had experience designing STEM experiments in a laboratory, such that measuring performance in this way would have little meaning. In light of this, single items can be used with adequate predictive validity (Bergkvist and Rossiter, 2007; Bergkvist, 2015), provided, as in any case of validity, that the implications and conclusions are appropriately bounded by the chosen measures (Kane, 1992). In our Discussion, we are careful to articulate the utility of this work given the way we define and measure the constructs.

\section{Control Variables}

We also solicited self-reported information for a variety of demographic variables, including gender and home support. We chose to control for student gender and home science support in light of their persistent effects on STEM identity regardless of the student population sampled (e.g., undergraduate STEM majors broadly, Rodriguez et al., 2019; undergraduate STEM majors in an introductory physics course, Seyranian et al., 2018; undergraduate students in an introductory psychology course, Starr et al., 2018). Although much research suggests that Hispanic ethnicity is associated with challenges developing STEM identity and STEM career aspirations (e.g., Aschbacher et al., 2010; Grossman and Porche, 2014; Rodriguez et al., 2019), the ethnicity variable was not significant in any of our models and decreased the statistical validity of the models, so it was not included. This lack of significance is likely a feature of the context of our study, where Hispanic students constitute the majority of the student population (i.e., over 64\%) and where the county in which this study took place includes a predominantly Hispanic population. We return to this point in the Discussion, where we address the transferability of our results.

Seventy-five percent of our respondents self-identified as "female" and 77\% indicated having home environments supportive of science (i.e., "Was your home environment supportive of science, for example, did you often visit science museums, or zoos?"). We also chose to test for the effects of whether or not respondents indicated pursuit of a biological sciences major in particular due to the preponderance of pre-med/health students that typically enroll in this disciplinary track, which may or may not have a particular effect on their self-perceptions as STEM people (Cotner et al., 2017). We created this variable as a binary based on respondents' selection of "biological sciences" as their major versus any of the other STEM majors listed.

\section{Data Analyses}

We tested four linear multiple regression models to examine the relationships between these variables. All models included the following independent, categorical variables: pre-med/ health student (binary), gender (binary), and home support of science (categorical: "yes," "no," "not sure"). Students' self-reported gender and level of home support of science were included as control variables, given their predictive power in various STEM identity models (e.g., Crisp et al., 2009; Cribbs et al., 2015; Godwin et al., 2016). Before running our regression models, we tested for potential random effects present in our binary "biological sciences major" 
variable, that is, we examined whether variance in our outcome variables could be explained by both between- and within-group differences (Theobald, 2018). This decision was based on the fact that pre-med/health respondents were more likely to be pursuing a biological sciences major. We found no between- or within-group differences, suggesting that students' pursuit of a biological sciences major was not associated with their responses to our STEM identity items. As such, we removed pursuit of a biological sciences major as a control variable from our models; Akaike information criterion values confirmed in all cases that the models without this variable presented a better "fit."

The four regression models differed in terms of their outcome variables, which were treated as continuous. Model 1 explored the relationship between our independent variables and STEM identity as our outcome. We took a similar approach with models 2,3 , and 4, looking at the relationships between our independent variables and performance-competence, recognition, and interest in STEM, respectively. Although we found only a small number of instances of missingness across our data (3\%), we ran a single expectation-maximization imputation (Honaker et al., 2011; Rubin, 1996). All analyses were run using R software.

\section{RESULTS}

Model 1 was statistically significant, $F(4,483)=2.56, p<0.05$, $R^{2}=0.02$, in predicting STEM identity $(\mathrm{M}=4.51 ; \mathrm{SE}=0.03)$. Specifically, while controlling for gender and home support, we found that pre-med/health students were more likely to see themselves as STEM people than those who did not indicate pursuing a pre-med/health track $(\beta=-0.10 ; p<0.05)$. Participant gender and home science support were not significant predictors.
Model 2 was statistically significant, $F(4,483)=4.56, p=$ $0.001, R^{2}=0.04$, in predicting STEM performance-competence $(M=4.13$; $S E=0.04)$. Among demographic factors, students who identified as male were more likely to score higher on this item than those who identified as female $(\beta=-0.11 ; p<0.05)$. Those who indicated having home support around science were significantly more likely to score higher on our STEM performance-competence item compared with those who did not indicate home science support $(\beta=-0.16 ; p<0.001)$. Students' pursuit of pre-med/health careers was not significantly associated with their STEM performance-competence measures.

Model 3 was significant, $F(4,483)=5.39, p<0.001, R^{2}=$ 0.04 , in predicting students' perceptions that their teachers see them as STEM people (i.e., recognition; $\mathrm{M}=4.15$, $\mathrm{SE}=0.04$ ). Those pursuing a pre-med/health track were more likely to perceive that recognition than those not on a pre-med/health track $(\beta=-0.12 ; p=0.01)$. On the other hand, women were less likely to have that perception than men $(\beta=-0.10 ; p<0.05)$. Model outcomes indicated that those who were not sure that they had a home supportive of science $(\beta=-0.14 ; p<0.01)$ were also less likely to believe their teachers see them as STEM people than those students who indicated having that support. Not having home support was not a significant predictor, although our $p$ value approaches our cutoff $(\beta=-0.09 ; p=$ 0.06).

Model 4 was not significant, $F(4,483)=0.88, p=0.48, R^{2}=$ 0.01 , meaning that we found no relationship between our variables and interest in learning more about STEM. See Table 1 for a summary of model outcomes.

\section{DISCUSSION}

In light of the many relationships that researchers have noted between STEM identity and the experiences of undergraduate

TABLE 1. Summary of linear regression models, each of which tested the same predictors on four different outcome variables: STEM identity, performance-competence, recognition, and interest, respectively

\begin{tabular}{|c|c|c|c|c|c|c|c|c|}
\hline \multicolumn{9}{|c|}{ Regression coefficients } \\
\hline \multirow[b]{2}{*}{ Predictor } & \multicolumn{2}{|c|}{$\begin{array}{c}\text { Model } 1 \\
\text { (STEM identity) }\end{array}$} & \multicolumn{2}{|c|}{$\begin{array}{c}\text { Model 2 } \\
\text { (performance-competence) }\end{array}$} & \multicolumn{2}{|c|}{$\begin{array}{c}\text { Model } 3 \\
\text { (recognition) }\end{array}$} & \multicolumn{2}{|c|}{$\begin{array}{c}\text { Model } 4 \\
\text { (interest) }\end{array}$} \\
\hline & $\beta$ & $t$ & $\beta$ & $t$ & $\beta$ & $t$ & $\beta$ & $t$ \\
\hline $\begin{array}{l}\text { Students not on a pre-med/health track } \\
\text { compared with those on a pre-med/ } \\
\text { health track }\end{array}$ & $-0.10^{*}$ & -2.18 & -0.06 & -1.28 & $-0.12^{* *}$ & -2.54 & -0.07 & -1.57 \\
\hline $\begin{array}{l}\text { Students not indicating home science } \\
\text { support compared with those who } \\
\text { reported science support }\end{array}$ & -0.06 & -1.22 & $-0.16 * * *$ & -3.52 & $-0.09 !$ & -1.89 & -0.03 & -0.71 \\
\hline $\begin{array}{l}\text { Students not sure of home science } \\
\text { support compared with those who } \\
\text { reported science support }\end{array}$ & -0.07 & -1.54 & -0.04 & -0.94 & $-0.14 * *$ & -3.17 & -0.03 & -0.62 \\
\hline$p$ value & \multicolumn{2}{|c|}{$<0.05$} & \multicolumn{2}{|c|}{0.001} & \multicolumn{2}{|c|}{$<0.01$} & \multicolumn{2}{|c|}{0.48} \\
\hline
\end{tabular}

! $p$ value $=0.06$.

*Value is significant, $p<0.05$.

$* *$ Value is significant, $p<0.01$

$* * *$ Value is significant, $p<0.001$. 
STEM students, the purpose of our study was to explore the extent to which STEM majors with the intent to pursue medical or health careers identify as STEM people relative to STEM majors not pursuing those occupations. Given that the majority of pre-med/health students do not ultimately go to medical school (Association of American Medical Colleges, 2021), we see this work as an important step in understanding the opportunities that may be theoretically accessible to this population but underrealized due to an absence of research that assesses the STEM identity of this population. We couch this aim in both prior research on pre-med/health students that identifies large gaps in studies of the undergraduate pre-med/health experience (Lin et al., 2013), as well as national reports and initiatives that overlook this large portion of the STEM population (e.g., Committee on STEM Education, 2018). These gaps are made more obvious when compared with the large body of research on undergraduate STEM majors pursuing fields like physics (NRC, 2013), engineering (NRC, 2012), or computer science (NASEM, 2018). Thus, we position our research as an initial step in understanding a population that, despite its large size, is rarely studied as a unit, even though they share identity-related experiences that are likely to be of interest to educators and researchers. For instance, this population of students share aspirations to highly competitive postbaccalaureate education (e.g., medical school) and, consequently, often must decide on new career directions late in their undergraduate education experience. Thus, we conjecture that this understanding could particularly be of interest to educators and researchers concerned with retaining students in STEM careers in cases in which they have been redirected from their "first choice" aspiration.

Our models indicated that STEM majors on a pre-med/ health track were more likely to have a greater sense of STEM identity and perceive that their teachers see them as STEM people, whereas interest in learning more about STEM and sense of performance-competence on tests and exams in STEM were not associated with pre-med/health status. Collectively, these findings suggest that, in some ways, pre-med/health students associate themselves with STEM more so than other STEM majors. These findings run counter to stereotypes of pre-med/ health students as caring only about their grades or as seeking only the extension of their STEM degree (i.e., qualifying for medical school) rather than having an inherent affinity toward STEM subjects (Sade et al., 1984). On the other hand, our work complements more recent findings, like those of Pacifici and Thomson (2011), that posit pre-med/health students as equally interested in and motivated to engage in authentic, laboratory-based learning experiences as their non-pre-med/health counterparts, as well as those of Larson et al. (2012) showing pre-med/health students as having higher science and math interest and self-efficacy in addition to career-related goals. Larson et al.'s (2012) study is particularly relevant given its juxtaposition with our study in terms of outcomes and student populations, which we address later.

Despite research that suggests that instructors may hold unfavorable stereotypes about their pre-med/health students (Sade et al., 1984), our results indicate that these students feel more strongly than their peers that their instructors recognize them as STEM people. Given that our pre-med/health respondents were more likely to see themselves as STEM persons, their perceptions of how instructors see them are not surprising, as research using the identity frameworks of Carlone and Johnson (2007) and Hazari et al. (2010) consistently argues that being recognized as a STEM person has the highest effect on STEM identity (e.g., Dou et al., 2019). There are several possible implications of this outcome that warrant further exploration. First, this suggests the plausibility that faculty behaviors toward and interactions with pre-med/health students can be encouraging and affirming of their identification with STEM. Although we did not seek to confirm students' perceptions from the perspectives of faculty, identity negotiation and renegotiation occur as a result of, rather than in spite of, interactions with members of the in-group (Kim et al., 2018), which in our case would consist of faculty. In other words, the influence of being recognized as a kind of person, from an identity perspective, is more related to how it is perceived by the individual rather than how it was intended by the person giving (or withholding) recognition. Again, this approach lies in contrast to the work of Sade et al. (1984), which, not adopting a personal identity framework, did not survey the perspectives of pre-med/health students. Working with life science undergraduates, postgraduates, and faculty, Aikens et al. (2016) provide complementary evidence supporting the important role of faculty, finding that undergraduate students who worked closely with faculty and postgraduates on academic research reported higher scientific identity and intentions to enroll in PhD programs than students who worked with postgraduates alone.

Larson et al. (2012) present equally favorable views of premed/health students pursuing STEM majors using a similar approach to our own, though on the surface our findings appear contradictory. While we did not find significant relationships between our participants' interest in learning more about STEM and academic performance-competence with regard to their pre-med/health status, Larson et al. (2012) found that students pursuing medical careers were more likely to report higher science and math interest and self-efficacy (a construct conceptually related to performance-competence). This apparent contradiction should be interpreted in light of differences in our contexts. Their study involved mostly male students (61.9\%) at a large midwestern university with respondents who primarily identified as White (non-Hispanic), while our study involved mostly female students at a large southeastern university where the majority identifies as Hispanic. Moreover, their study included primarily "science" majors (as opposed to "STEM" majors) recruited from introductory science courses that did not include math courses. Their final models also do not account for the variance explained by participant gender and home support. Moreover, when comparing undergraduate science majors seeking medical careers with those pursuing graduate school, Larson et al. (2012) find no differences in math and science interest and self-efficacy. When considering those findings in light of those of our study, we find they affirm that, in particular academic contexts, students pursuing medical degrees are, at worst, just as interested and confident in science and mathematics as science majors not pursuing medical degrees, and, at best, more interested and feel more competent. Collectively, the juxtaposition of our work and that of Larson and colleagues further implies the need to understand the pre-med/health experiences of students within unique contexts that account for the intersection of gender and racial identities, as well as the need to explore these constructs with different comparison 
groups to understand the vagaries of the pre-med/health experience across contexts.

While we aim to shine a positive light on undergraduate premed/health students and their career intentions, the more than $50 \%$ that will not enter medical school due to overwhelming challenges (Association of American Medical Colleges, 2021) may consist of a population of students who already identify with STEM and can be inspired and motivated to pursue equally fulfilling graduate and professional STEM careers rather than abandon STEM altogether. Although Villarejo et al. (2008) included data from a wider variety of participants, their data from doctoral students pursuing biomedicine $\mathrm{PhDs}$ indicated that half reported starting their undergraduate careers seeking to become medical doctors, having "discovered their interest in science research after entering college" (p. 402). In this way, Villarejo et al. (2008) specifically drew attention to pre-med students as a population that can be spurred to pursue nonmedical STEM careers through undergraduate research experiencesparticularly those who are underrepresented in science. This suggestion is consistent with a broader notion that engagement in authentic science that invites students to engage in scientific practices can enhance science attitudes and lead to commitments in pursuing science careers (Syed et al., 2018). Given that students who intend to enter medical school may be in a position to rethink their aspirations during or after graduation (e.g., those who defer applying to medical school), research is needed to determine the extent to which such opportunities may sustain students' interest in pursuing STEM careers, even when removed from the university experience for a semester or more.

In our models, gender played a role in the degree to which students felt recognized by their teachers as STEM persons and their performance-competence on tests and exams-with female students tending to report slightly lower positive perceptions of both teacher recognition and test performance-competence. Nevertheless, association with gender did not extend to STEM interest or identity as a whole. However, these results should not be taken to mean that gender is not a significant factor in STEM identity, especially given the corpus of research suggesting the contrary in different contexts (e.g., Archer et al., 2013; Kim et al., 2018; Seyranian et al., 2018; Starr, 2018; Witherspoon et al., 2019). For instance, Witherspoon et al. (2019) investigated why women are far less likely to continue pursuing medical school than are men in spite of their interest in obtaining medical degrees. While they found that this phenomenon could not be attributed to how well the students performed academically, it did seem to be rooted in their sense of their capabilities in the subject, or competency beliefs. Instead, our results do provide some nuance in our understanding of what aspects of identity may be affected by gender and with what populations-it is important to note that our work was done with students in introductory STEM courses, whereas Witherspoon and colleagues studied student trends across their college careers.

It is also important to recognize that our study involved the participation of students who had exhibited some success in STEM fields, given their enrollment in introductory STEM courses and intent to pursue careers in those fields; they are therefore more likely to have higher levels of STEM interest, performance-competence, and identity than a general population might. In this way, the typically observed gender influence may be mitigated. This suggestion is supported by McDonald et al.'s (2019) analysis, which observed higher STEM identity in men than women in their sample as a whole (i.e., STEM and non-STEM majors) but statistically insignificant differences when the sample was restricted to those in the sample who were in "hard-STEM" majors. Additionally, the academic lean of our items, discussed previously, may not account for gendered differences that might be more distinct, for instance, if participants were asked whether they felt they would be seen as STEM persons by employees of a large technology company. That said, our female respondents were slightly less likely to perceive their teachers as recognizing them as STEM persons, plausibly aligning with sociocultural perceptions of STEM people as traditionally masculine.

\section{LIMITATIONS AND FUTURE DIRECTIONS FOR RESEARCH}

In interpreting these findings, it is important to keep in mind how these constructs were operationalized in order to make clear the extent to which our results may be interpreted and the areas where further research is needed. Identity and identity-related items were articulated in such a way as to allow a more granular examination of how pre-med/health students see themselves in undergraduate, academic contexts where they most saliently practice and author their STEM identities. This enables more specific recommendations for the higher education community, for example, regarding the design of academic opportunities (e.g., research) and other activities (e.g., advising) in ways that support STEM identity development. Other ways of measuring these identity precursors could offer additional insights into how pre-med/health students perceive themselves within the STEM enterprise beyond the classroom setting. For example, our items do not address the role that parents or peers play in contributing to students' sense of recognition as a STEM person (Kim et al., 2018), nor do they address students' performance-competence relevant to STEM-related skills, such as designing experiments or using evidence to build a logical argument. Further, the selection of survey methods allowed us to quantitatively identify the relationships between pre-med/health status, STEM identity, and identity precursors. While we see this as an important first step in exploring the experiences of these students, we acknowledge the limitations of quantitative methods in explaining the pre-med/health experience in richer detail, as could be achieved with qualitative data. Interviews that we have done with 20 of our surveyed students support the results presented in this work, and we are currently engaged in more in-depth interview analysis that will further address the research questions explored in this paper.

As noted earlier, we also highlight that our study refers to these constructs from the perspective of the student. This delimitation is particularly noteworthy for the item "My teachers see me as a STEM person," which requires respondents to make judgments that may not accurately reflect their teachers' perceptions. We emphasize here that, in terms of STEM identity development, what is important are students' perceptions of their instructors' beliefs (Gee, 2000). Similarly, our lack of knowledge regarding students' perceptions of the term "STEM" limits our ability to generalize across different conceptions of STEM (e.g., as an integrated discipline, as problem-solving skills, as a philosophical paradigm, as a collection of related disciplines). 
In our Discussion, we advocate for providing equivalent experiences to pre-med/health students and their non-premed/health peers that support STEM identity development (e.g., research experiences in non-medical STEM fields). However, in making these recommendations we must acknowledge the dearth of information on pre-med/health undergraduate experiences (e.g., participation in STEM research) and career outcomes (e.g., where they go if they do not get into medical school) in aggregate. Lin et al. (2013) note that the pre-med/ health student population is particularly challenging to identify and sample. Their review found the following:

Studies used a variety of definitions of a Pre-Medical student to identify their samples of interest. Some studies used the Association of American Medical Colleges (AAMC) data on the MCAT to identify their samples. Others used enrollment in pre medical-required courses as indicators. Those authors with connections to the Pre-Medical advising structure used email lists and social networks to recruit participants and the most common sampling method was self-identification by the student. Each of these methods yielded slightly different samples of Pre-Medical students, which, in turn, can influence the conclusions drawn. (p. 35)

This inconsistency in classification across research and programs and rudimentary ways of tracking this population within institutions precludes a better understanding of the identity-related experiences of pre-med/health students. Our own literature review revealed myriad ways that researchers employ the terms "pre-med" or "pre-medical" careers, with some referring exclusively to those with intentions to attend a medical school (e.g., Liang, 2012); some using the terms to refer to students with intentions to attend postbaccalaureate training encompassing a broader set of health careers that include medicine, nursing, and even veterinary careers (e.g., Larson et al., 2012); some using the terms "premedicine" and "prehealth" interchangeably (e.g., NRC, 2003); and still others who did not define their terminology (e.g., Fink et al., 2020). Thus, efforts to understand and improve the experiences of pre-med/health students must contend with this messy approach to tracking and studying recruitment of the pre-med/health student population.

Complicating this tracking further are the relatively high failure rates in STEM courses (Seymour and Hewitt, 1997; Webb et al., 2014) and frequent change out of STEM courses, particularly for marginalized groups (Seymour and Hewitt, 1997; Crisp et al., 2009; Riegle-Crumb et al., 2019). In our research, we surveyed students in introductory STEM courses-a point in their college careers when they may not have yet encountered such challenges to their STEM identities, performance in STEM, or recognition by teachers in STEM. Thus, it is possible that the same students we surveyed would report differently if they were to be questioned later in their undergraduate careers-a valuable avenue for future, longitudinal research. However, when positioning our work identifying the high degree of STEM identity of pre-med/health students alongside this vulnerability, we see a greater imperative to create opportunities for students to experience identity-supportive experiences that could retain STEM aspirations in the face of setbacks, whether they occur early in their college careers, such as by failing an introductory course, or later, such as when experiencing rejection from medical school.

\section{CONCLUSION}

Though STEM identity frameworks have been used to understand the experiences of college students pursuing a variety of STEM subfields, like undergraduate mathematics (Cribbs et al., 2015, 2016) and engineering (Godwin et al., 2016), a specific focus on pre-med/health students has gone largely absent. Neglecting to address this population in studies of STEM identity, academic performance, and career choice, could continue to limit funding and programmatic prioritization at both local (e.g., university) and national (e.g., federal priorities) levels. This is particularly noteworthy, given the large proportion of pre-med/health students who do not attend medical school and therefore may be at greater risk of leaving STEM professions altogether compared with other college STEM students.

In our research, we compared STEM majors pursuing medical or health careers with those who did not indicate this intent. Our findings contribute to contemporary evidence dispelling outdated depictions of pre-med/health students as not authentic in their engagement with STEM fields. However, we note that our results are an assessment of how pre-med/health students see themselves - not how others see them. This is an important distinction, particularly in contexts in which negative stereotypes of pre-med/health students preclude important others, such as faculty, from recognizing their authentic engagement. This mismatch could contribute to disappointment or disenchantment with STEM, which could have further implications for students' persistence in STEM, particularly for those who do not enter medical school. This implication warrants broader investigation across contexts, but such studies will continue to face obstacles for lack of structured systems that track the experiences and successes of pre-med/health students. We hope our findings and those referenced in this study draw attention to these challenges in ways that support others seeking to enhance the undergraduate pre-med/health student experience and STEM career journey.

\section{ACKNOWLEDGMENTS}

This work was in part supported by the NSF CAREER Award AISL-1846167. Any opinions, findings, and conclusions or recommendations expressed in these materials are those of the authors and do not necessarily reflect the views of the NSF.

\section{REFERENCES}

Aikens, M. L., Sadselia, S., Watkins, K., Evans, M., Eby, L. T., \& Dolan, E. L. (2016). A social capital perspective on the mentoring of undergraduate life science researchers: An empirical study of undergraduate-postgraduate-faculty triads. CBE-Life Sciences Education, 15,(2), ar16.

Archer, L., Dawson, E., DeWitt, J., Seakins, A., \& Wong, B. (2015). "Science capital": A conceptual, methodological, and empirical argument for extending Bourdieusian notions of capital beyond the arts. Journal of Research in Science Teaching, 52(7), 922-948.

Archer, L., DeWitt, J., Osborne, J., Dillon, J., Willis, B., \& Wong, B. (2010). "Doing" science versus "being" a scientist: Examining 10/11-year-old schoolchildren's constructions of science through the lens of identity. Science Education, 94(4), 617-639.

Archer, L., DeWitt, J., Osborne, J., Dillon, J., Willis, B., \& Wong, B. (2013) "Not girly, not sexy, not glamorous": Primary school girls' and parents constructions of science aspirations. Pedagogy, Culture and Society. 21(1), 171-194

Aschbacher, P. R., Li, E., \& Roth, E. J. (2010). Is science me? High school students' identities, participation and aspirations in science, engineering and medicine. Journal of Research in Science Teaching, 47(5), 564-582. 
Association of American Medical Colleges. (2021). U.S. medical school applications and matriculants by school, state of legal residence, and sex. Retrieved April 7, 2021, from https://www.aamc.org/media/5976/download

Avraamidou, L. (2020). Science identity as a landscape of becoming: Rethinking recognition and emotions through an intersectionality lens. Cultural Studies of Science Education, 15, 323-345.

Bandura, A. (1989). Human agency in social cognitive theory. American Psychologist, 44(9), 1175.

Bandura, A. (2001). Social cognitive theory: An agentic perspective. Annual Review of Psychology, 52(1), 1-26.

Bergkvist, L. (2015). Appropriate use of single-item measures is here to stay. Marketing Letters, 26, 245-255.

Bergkvist, L., \& Rossiter, J. R. (2007). The predictive validity of multiple-item versus single-item measures of the same constructs. Journal of Marketing Research, 44(2), 175-184.

Biglan, A. (1973). The characteristics of subject matter in different academic areas. Journal of Applied Psychology, 57, 195-203.

Calabrese Barton, A., Kang, H., Tan, E., O'Neill, T. B., Bautista-Guerra, J., \& Brecklin, C. (2013). Crafting a future in science: Tracing middle school girls' identity work over time and space. American Educational Research Journal, 50(1), 37-75.

Carlone, H. B., \& Johnson, A. (2007). Understanding the science experiences of successful women of color: Science identity as an analytic lens. Journal of Research in Science Teaching, 44(8), 1187-1218.

Cass, C. A. P., Hazari, Z., Cribbs, J., Sadler, P. M., \& Sonnert, G. (2011). Examining the impact of mathematics identity on the choice of engineering careers for male and female students. Paper presented at: 41st ASEE/IEEE Frontiers in Education Conference (Rapid City, SD), 1-5.

Chang, M. J., Sharkness, J., Hurtado, S., \& Newman, C. B. (2014). What matters in college for retaining aspiring scientists and engineers from underrepresented racial groups. Journal of Research in Science Teaching, 51(5), 555-580.

Chen, A. (2017). From pre-med to physician: Pursuing a medical career Retrieved April 7, 2021, from https://www.bls.gov/careeroutlook/2017/ article/premed.htm?view_full

Committee on STEM Education. (2018). Charting a course for success: America's strategy for STEM education. Washington, DC: White House National Science \& Technology Council. Retrieved April 7, 2021, from https:// www.energy.gov/sites/prod/files/2019/05/f62/STEM-Education-Strategic -Plan-2018.pdf

Conrad, P. (1986). The myth of cut-throats among pre-medical students: On the role of stereotypes in justifying failure and success. Journal of Health and Social Behavior, 27, 150-160.

Cotner, S., Thompson, S., \& Wright, R. (2017). Do biology majors really differ from non-STEM majors? CBE-Life Sciences Education, 16(3), ar48.

Cribbs, J. D., Cass, C., Hazari, Z., Sadler, P. M., \& Sonnert, G. (2016). Mathematics identity and student persistence in engineering. The International Journal of Engineering Education, 32(1), 163-171.

Cribbs, J. D., Hazari, Z., Sonnert, G., \& Sadler, P. M. (2015). Establishing an explanatory model for mathematics identity. Child Development, 86(4), 1048-1062.

Crisp, G., Nora, A., \& Taggart, A. (2009). Student characteristics, pre-college, college, and environmental factors as predictors of majoring in and earning a STEM degree: An analysis of students attending a Hispanic serving institution. American Educational Research Journal, 46(4), 924 942

Diekman, A. B., Clark, E. K., Johnston, A. M., Brown, E. R., \& Steinberg, M. (2011). Malleability in communal goals and beliefs influences attraction to STEM careers: Evidence for a goal congruity perspective. Journal of Personality and Social Psychology, 101(5), 902

Dou, R., \& Cian, H. (2020). The relevance of childhood science talk as a proxy for college students' STEM identity at a Hispanic Serving Institution. Research in Science Education, 50, 1-13. https://doi.org/10.1007/ s11165-020-09928-8

Dou, R., Hazari, Z., Dabney, K., Sonnert, G., \& Sadler, P. (2019). Early informal STEM experiences and STEM identity: The importance of talking science. Science Education, 103(3), 623-637.

Emery, C. R., Boatright, D., \& Culbreath, K. (2018). Stat! An action plan for replacing the broken system of recruitment and retention of underrepresented minorities in medicine (NAM Perspectives discussion paper). Washington, DC: National Academy of Medicine.

Estrada, M., Burnett, M., Campbell, A. G., Campbell, P. B., Denetclaw, W. F. Gutiérrez, C. G., ... \& Okpodu, C. M. (2016). Improving underrepresented minority student persistence in STEM. CBE-Life Sciences Education, 15(3), es5.

Estrada, M., Hernandez, P. R., \& Schultz, P. W. (2018). A longitudinal study of how quality mentorship and research experience integrate underrepresented minorities into STEM careers. CBE-Life Sciences Education, 17(1), ar9.

Fink, A., Frey, R. F., \& Solomon, E. (2020). Belonging in general chemistry predicts first-year undergraduates' performance and attrition. Chemistry Education Research and Practice, 21(4), 1042-1062.

Gee, J. (2000). Identity as an analytic lens for research in education. Review of Research in Education, 25, 99-125.

Godwin, A., Potvin, G., Hazari, Z., \& Lock, R. (2016). Identity, critical agency and engineering: An affective model for predicting engineering as a career choice. Journal of Engineering Education, 105(2), 312-340.

Goff, E. E., Mulvey, K. L., Irvin, M. J., \& Hartstone-Rose, A. (2020). The effects of prior informal science and math experiences on undergraduate STEM identity. Research in Science \& Technological Education, 38(3), 272-288.

Gokpinar, T., \& Reiss, M. (2016). The role of outside-school factors in science education: A two-stage theoretical model linking Bourdieu and Sen, with a case study. International Journal of Science Education, 38(8), $1278-$ 1303.

Grossman, J. M., \& Porche, M. V. (2014). Perceived gender and racial/ethnic barriers to STEM success. Urban Education, 49(6), 698-727.

Hazari, Z., \& Cass, C. (2018). Towards meaningful physics recognition: What does this recognition actually look like? Physics Teacher, 56(7), 442-446

Hazari, Z., Sonnert, G., Sadler, P. M., \& Shanahan, M. C. (2010). Connecting high school physics experiences, outcome expectations, physics identity, and physics career choice: A gender study. Journal of Research in Science Teaching, 47(8), 978-1003.

Hernandez, P. R., Bloodhart, B., Barnes, R. T., Adams, A. S., Clinton, S. M. Pollack, I., ... \& Fischer, E. V. (2017). Promoting professional identity, motivation, and persistence: Benefits of an informal mentoring program for female undergraduate students. PLOS ONE, 12(11), e018753.

Heybach, J., \& Pickup, A. (2017). Who is STEM? Disrupting the gender crisis within STEM. Educational Studies, 53(6), 614-627.

Hoeppner, B. B., Kelly, J. F., Urbanoski, K. A., \& Slaymaker, V. (2011). Comparative utility of a single-item versus multiple-item measure of self-efficacy in predicting relapse among young adults. Journal of Substance Abuse Treatment, 41(3), 305-312.

Honaker, J., King, G., \& Blackwell, M. (2011). AMELIA II: A program for missing data. Journal of Statistical Software, 45(7), 1-54.

Horowitz, G. (2009). It's not always just about the grade: Exploring the achievement goal orientations of pre-med students. Journal of Experimental Education, 78(2), 215-245.

Kane, M. T. (1992). An argument-based approach to validity. Psychological Bulletin, 112(3), 527

Kim, A. Y., Sinatra, G. M., \& Seyranian, V. (2018). Developing a STEM identity among young women: A social identity perspective. Review of Educational Research, 88(4), 589-625.

Larson, L. M., Bonitz, V. S., Werbel, J. D., Wu, T.-F., \& Mills, L. R. (2012). Distinguishing beginning pre-med students from their science peers. Journal of Career Assessment, 20(2), 208-220

Lent, R. W., Brown, S. D., \& Hackett, G. (1994). Toward a unifying social cognitive theory of career and academic interest, choice, and performance. Journal of Vocational Behavior, 45, 79-122.

Lett, L. A., Orji, W. U., \& Sebro, R. (2018). Declining racial and ethnic representation in clinical academic medicine: A longitudinal study of 16 US medical specialties. PLOS ONE, 13(11), e0207274.

Liang, A. (2012, December 7). The premed stereotype: Is being competitive and grade obsessed the right way to approach medical school. The Tech Retrieved April 7, 2021, from https://thetech.com/2012/12/07/liang-v132-n59

Lin, K. Y., Parnami, S., Fuhrel-Forbis, A., Anspach, R. R., Crawford, B., \& Vries R. G. D. (2013). The undergraduate pre-medical experience in the United 
States: A critical review. International Journal of Medical Education, 4, 26-37.

Lock, R. M., \& Hazari, Z. (2016). Discussing underrepresentation as a means to facilitating female students' physics identity development. Physical Review Physics Education Research, 12(2), 020101

Luhtanen, R., \& Crocker, J. (1992). A collective self-esteem scale: Self-evaluation of one's social identity. Personality and Social Psychology Bulletin, 18(3), 302-318

McDonald, M. M., Zeigler-Hill, V., Vrabel, J. K., \& Escobar, M. (2019). A single-item measure for assessing STEM identity. Frontiers in Education, 4 $\operatorname{ar} 78$

Morris, B. J., Owens, W., Ellenbogen, K., Erduran, S., \& Dunlosky, J. (2019). Measuring informal STEM learning supports across contexts and time. International Journal of STEM Education, 6(1), 40.

Morton, T. R., \& Parsons, E. C. (2018). \# BlackGirlMagic: The identity conceptualization of Black women in undergraduate STEM education. Science Education, 102(6), 1363-1393.

Moss, A. (2018, November 9). Confessions from "cutthroat brown-nosers": Premed students talk stereotypes and their truth. The Weekender. Retrieved April 7, 2021, from https://www.dailycal.org/2018/11/09/confessions -from-cutthroat-brown-nosers-pre-med-students-talk-stereotypes -and-their-truth/

Mraz-Craig, J. A., Daniel, K. L., Bucklin, C. J., Mishra, C., Ali, L., \& Clase, K. L. (2018). Student identities in authentic course-based undergraduate research experience. Journal of College Science Teaching, 48(1), 68-75.

Nadelson, L. S., McGuire, S. P., Davis, K. A., Farid, A., Hardy, K. K., Hsu, Y. C., ... \& Wang, S. (2017). Am I a STEM professional? Documenting STEM student professional identity development. Studies in Higher Education, 42(4), 701-720

National Academies of Sciences, Engineering, and Medicine (NASEM). (2016). Promising practices for strengthening the regional STEM workforce development ecosystem. Washington, DC: National Academies Press.

NASEM. (2018). Assessing and responding to the growth of computer science undergraduate enrollments. Washington, DC: National Academies Press. https://doi.org/10.17226/24926

NASEM. (2020). Promising practices for addressing the underrepresentation of women in science, engineering, and medicine: Opening doors. Washington, DC: National Academies Press.

National Research Council (NRC). (2003). BIO2010: Transforming undergraduate education for future research biologists. Washington, DC: National Academies Press.

NRC. (2012). Discipline-based education research: Understanding and improving learning in undergraduate science and engineering. Washington, DC: National Academies Press.

NRC . (2013). Adapting to a changing world: Challenges and opportunities in undergraduate physics education. Washington, DC: National Academies Press.

National Science Board. (2015). Revisiting the STEM workforce: A companion to science and engineering indicators 2014. Arlington, VA: National Science Foundation. Retrieved April 7, 2021, from https://nsf.gov/ pubs/2015/nsb201510/nsb201510.pdf

National Science Board. (2020). About the NSB. Retrieved April 7, 2021, from https://www.nsf.gov/nsb/about/index.jsp

National Science Foundation. (2020). Science and engineering indicators 2020: The state of U.S. science and engineering. Arlington, VA. Retrieved April 7, 2021, from https://ncses.nsf.gov/pubs/nsb20201/

Ong, M. (2005). Body projects of young women of color in physics: Intersections of gender, race, and science. Social Problems, 52, 593-617.

Pacifici, L. B., \& Thomson, N. (2011). Undergraduate science research: A comparison of influences and experiences between Pre-Med and NonPre-Med students. CBE-Life Sciences Education, 10(2), 199-208.

Pattison, S. A., \& Dierking, L. D. (2019). Early childhood science interest development: Variation in interest patterns and parent-child interactions among low-income families. Science Education, 103(2), 362-388.
Riegle-Crumb, C., King, B., \& Irizarry, Y. (2019). Does STEM stand out? Examining racial/ethnic gaps in persistence across postsecondary fields. Educational Researcher, 48(3), 133-144.

Robinson, K. A., Perez, T., Carmel, J. H., \& Linnenbrink-Garcia, L. (2019). Science identity development trajectories in a gateway college chemistry course: Predictors and relations to achievement and STEM pursuit. Contemporary Educational Psychology, 56, 180-192.

Rodriguez, S., Cunningham, K., \& Jordan, A. (2019). STEM identity development for Latinas: The role of self-and outside recognition. Journal of Hispanic Higher Education, 18(3), 254-272.

Rubin, D. B. (1996). Multiple imputation after 18 + years. Journal of the American Statistical Association, 91(434), 473-489.

Sade, R. M., Fleming, G. A., \& Ross, G. R. (1984). A survey on the "Pre-Medical syndrome." Academic Medicine, 59(5), 386-391.

Seymour, E., \& Hewitt, N. M. (1997). Talking about leaving: Why undergraduates leave the sciences. Boulder, CO: Westview Press.

Seyranian, V., Madva, A., Duong, N., Abramzon, N., Tibbetts, Y., \& Harackiewicz, J. M. (2018). The longitudinal effects of STEM identity and gender on flourishing and achievement in college physics. International Journal of STEM Education, 5(1), 40.

Shanahan, M. C. (2008). What does it mean to be a science person? Exploring the meaning and impact of identity development in science. Paper presented at: Canadian Society for the Study of Education annual conference (Vancouver, BC, Canada).

Starr, C. R., Hunter, L., Dunkin, R., Honig, S., Palomino, R., \& Leaper, C. (2020) Engaging in science practices in classrooms predicts increases in undergraduates' STEM motivation, identity, and achievement: A short-term longitudinal study. Journal of Research in Science Teaching, 57(1), 21623.

Stets, J. E., Brenner, P. S., Burke, P. J., \& Serpe, R. T. (2017). The science identity and entering a science occupation. Social Science Research, 64 $1-14$.

Syed, M., Zurbriggen, E. L., Chemers, M. M., Goza, B. K., Bearman, S., Crosby, F. J., ... \& Morgan, E. M. (2018). The role of self-efficacy and identity in mediating the effects of STEM support experiences. Analyses of Social Issues and Public Policy, 19(1), 7-49.

Taheri, M., Ross, M., Hazari, Z., Weiss, M., Georgiopoulos, M., Christensen, K., ... \& Chari, D. (2018, October). A structural equation model analysis of computing identity sub-constructs and student academic persistence. In 2018 IEEE Frontiers in Education conference (FIE) (pp. 1-7).

Taskinen, P. H., Schütte, K., \& Prenzel, M. (2013). Adolescents' motivation to select an academic science-related career: The role of school factors, individual interest, and science self-concept. Educational Research and Evaluation, 19(8), 717-733.

Theobald, E. (2018). Students are rarely independent: When, why, and how to use random effects in discipline-based education research. CBE-Life Sciences Education, 17(3), rm2.

Urrieta, L. (2007). Figured worlds and education: An introduction to the special issue. Urban Review, 39(2), 107-116.

Villarejo, M., Barlow, A. E. L., Kogan, D., Veazey, B. D., \& Sweeney, J. K. (2008). Encouraging minority undergraduates to choose science careers: Career paths survey results. CBE-Life Sciences Education, 7(4), 394-409.

Webb, D. C., Stade, E., \& Grover, R. (2014). Rousing students' minds in postsecondary mathematics: The undergraduate learning assistant model. Journal of Mathematics Education at Teachers College, 5(2).

Witherspoon, E. B., Vincent-Ruz, P., \& Schunn, C. D. (2019). When making the grade isn't enough: The gendered nature of premed science course attrition. Educational Researcher, 48(4), 193-204.

Wong, B. (2015). Careers "from" but not "in" science: Why are aspirations to be a scientist challenging for minority ethnic students? Journal of Research in Science Teaching, 52(7), 979-1002.

Xue, Y., \& Larson, R. C. (2015). STEM crisis or STEM surplus? Yes and yes. Monthly Labor Review. Retrieved April 7, 2021, from www.bls.gov/opub/ $\mathrm{mlr} / 2015 /$ article/stem-crisis-or-stem-surplus-yes-and-yes.htm 